\title{
An Identity Perspective on Ethical Leadership to Explain Organizational Citizenship Behavior: The Interplay of Follower Moral Identity and Leader Group Prototypicality
}

\author{
Fabiola H. Gerpott ${ }^{1} \cdot$ Niels Van Quaquebeke ${ }^{2} \cdot$ Sofia Schlamp $^{1} \cdot{\text { Sven C. } \text { Voelpel }^{3}}^{3}$
}

Received: 18 January 2017/ Accepted: 24 June 2017/Published online: 7 July 2017

(c) The Author(s) 2017. This article is an open access publication

\begin{abstract}
Despite the proliferation of research on ethical leadership, there remains a limited understanding of how specifically the assumingly moral component of this leadership style affects employee behavior. Taking an identity perspective, we integrate the ethical leadership literature with research on the dynamics of the moral self-concept to posit that ethical leadership will foster a sense of moral identity among employees, which then inspires followers to adopt more ethical actions, such as increased organization citizenship behavior (OCB). We further argue that these identity effects should be more pronounced when leaders are perceived to be group prototypical, as their actions then speak louder to followers' sense of identity. Two studiesa scenario experiment with 138 participants and a field study with 225 employees-provided support for our hypothesized moderated mediation model. Perceived ethical leadership positively affected OCB via followers'
\end{abstract}

Fabiola H. Gerpott

f.h.gerpott@vu.nl

Niels Van Quaquebeke

Niels.Quaquebeke@the-klu.org

Sofia Schlamp

sschlamp@gmail.com

Sven C. Voelpel

s.voelpel@jacobs-university.de

1 Vrije Universiteit Amsterdam, Van der Boechorststraat 1, 1081 BT Amsterdam, The Netherlands

2 Kühne Logistics University (KLU), Großer Grasbrook 17, 20457 Hamburg, Germany

3 Jacobs University Bremen, Campus Ring 1, Research IV, 28759 Bremen, Germany moral identity but only under conditions of high perceived leader group prototypicality. We discuss how the identity pathway of ethical leadership can facilitate novel theorizing about moral transference. Our findings also suggest that, when hiring external ethical leaders or training internal managers, practitioners are well advised to consider that these individuals may only be effective in morally transforming followers when they are perceived as prototypical for the group.

Keywords Ethical leadership · Moral identity · Group prototypicality · Organizational citizenship behavior (OCB) - Ethics

\section{Introduction}

Amidst the growing number of ethical scandals arising from organizations, scholars and practitioners alike have become increasingly aware that ethical leadership matters (e.g., Avey et al. 2012; Chen and Hou 2016; Drover et al. 2012; Reiley and Jacobs 2016). Despite this consensus, researchers only recently began to ponder whether there are unique moral components of ethical leadership that can explain the ensuing processes through which followers "change for the better" (Reynolds 2008; Sharif and Scandura 2014; van Gils et al. 2015b). This approach stands in contrast to previous undertakings that often treated ethical leadership as simply being another good type of leadership (cf. Hansen et al. 2013; Walumbwa et al. 2011).

In line with more general theorizing on leadership and identity (Epitropaki et al. 2017), recent work suggests that ethical leaders particularly speak to followers' moral selfconcept-i.e., their moral identity (Stets and Carter 
2012) - through their moral behavior (Zhu 2008; Zhu et al. 2016). The underlying reasoning is that the formation and salience of identity facets can change through work context factors such as leadership (Welbourne and Paterson 2017; Zhu et al. 2016), which in turn strongly informs behavior (van Knippenberg et al. 2004, 2005). As such, moral identity is no exception, in that it too is partly considered to be a fluid characteristic rather than a (relatively) fixed and unchanging feature (Jennings et al. 2015; Krettenauer and Hertz 2015).

With the present study, we extend the nascent identity lens on ethical leadership. Firstly, we seek to demonstrate the complete chain of effects, i.e., that changes in follower moral identity due to perceived ethical leadership in fact do translate to follower moral work outcomes such as employees' organizational citizenship behavior (OCB). Secondly, we aim to validate the causal mechanism implied in previous work (Zhu et al. 2016) through experimental designs with clear differentiation in cause and effect. And thirdly, we want to substantiate the identity rationale by examining its boundaries in greater detail (Spencer et al. 2005). To this end, we turn to the social identity model of organizational leadership (SIMOL, Hogg 2001; van Knippenberg 2011; van Knippenberg and Hogg 2003), which emphasizes that leaders are more effective at influencing subordinates when followers perceive them as group prototypical, i.e., as representing the group. It is then, the theory argues, that leaders speak more authoritatively to followers' identity.

In summary, we seek to link ethical leadership and identity theorizing more tightly. As such, we argue that, depending on the extent to which followers perceive ethical leaders to represent the group, the leader speaks more or less strongly to followers' moral identity, which ultimately translates to ethical follower actions at work (i.e., OCB). Our conceptual model is summarized in Fig. 1. We test our model in a scenario experiment with 138 participants and a field study with 225 employees. This multiple-study design allows us first to establish causality using a "clean" empirical design and second to replicate our findings in the field, which has the added benefit of providing external validity.

\section{Ethical Leadership and Followers' Organizational Citizenship Behavior}

Ethical leadership is commonly understood as "the demonstration of normatively appropriate conduct through personal actions and interpersonal relationships, and the promotion of such conduct to followers through two-way communication, reinforcement, and decision-making" (Brown et al. 2005, p. 120). According to Treviño et al. (2000, 2003), followers perceive ethical leaders on two dimensions: (1) whether the leader manages the ethical behavior of the team through communication, reinforcement, and visible actions (moral manager dimension) and (2) whether the leader is an ethical person, as indicated by his/her traits, behavior, and decision making as an individual (moral person dimension). The two facets of ethical leadership, however, show a high overlap such that managers tend to be perceived as either acting and being ethical or neither of the two. In other words, followers who ascribe ethical leadership to their supervisor assume that morality is an important part of the leader's self-concept and a guiding principle behind the leader's actions (Giessner et al. 2015).

A growing body of literature suggests that ethical leadership not only helps deter employees from negative moral behavior, such as discretionary workplace behavior, workplace incivility, or organizational deviance (e.g., Miao et al. 2012; Resick et al. 2013; Taylor and Pattie 2014; van Gils et al. 2015a, b) but can also inspire positive employees' behavior, such as OCB (Avey et al. 2011; Kacmar et al. 2011; Mo and Shi 2017; Newman et al. 2014). OCB refers to altruistic, voluntary activities that organizational members undertake outside of their job requirements and

Fig. 1 Conceptual model of the relationships between perceptions of ethical leadership, leader group prototypicality, follower moral identity, and organizational citizenship behavior

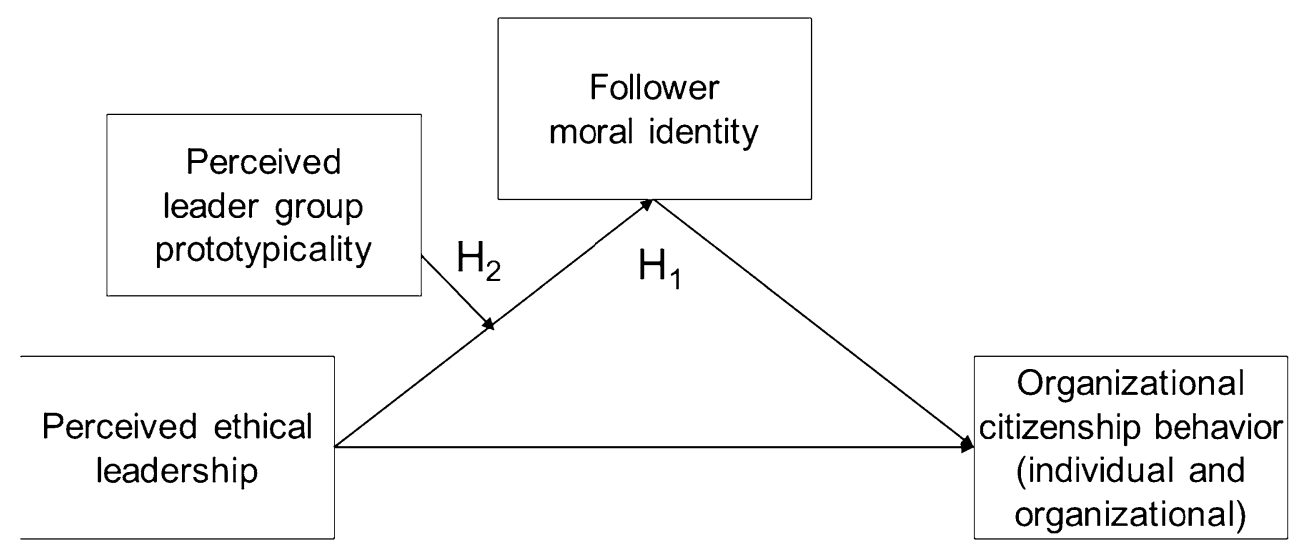


possibly without compensation (Organ 1988; Podsakoff et al. 2000). These activities can be directed at other organizational members (OCB individual) or the organization itself (OCB organizational; Williams and Anderson 1991). Employees who show high levels of individual-directed OCB will, for example, assist their supervisor or colleagues when they need help, make time to listen to them, and take a personal interest in their well-being. Meanwhile, employees who score high on organizationdirected OCB have high attendance rates, protect organizational property, adhere to informal rules, and avoid taking undeserved work breaks. Since both types of OCB can be considered morally appropriate workplace behavior, it is not surprising to note that ethical leadership has been identified as one of the main antecedents of such follower behavior (Avey et al. 2011; Kacmar et al. 2011).

Importantly, ethical leadership can be distinguished from other follower-oriented leadership styles (e.g., transformational leadership, authentic leadership, or participative leadership) through its foundational emphasis on moral motivations (van Gils et al. 2015a, b). This core idea of moral motives being the central driving force behind ethical leader behavior is supported by research showing that ethical leaders are indeed characterized by a higher moral identity (Giessner et al. 2015; Mayer et al. 2012; Skubinn and Herzog 2016; Zhu et al. 2016). Yet, surprisingly, so far there remains limited knowledge about the unique moral processes through which ethical leaders influence followers' OCB (Den Hartog 2015; Ng and Feldman 2015; van Gils et al. 2015a, b). In other words, the conceptualization of ethical leadership's underlying processes in previous studies largely neglected that moral leaders may change specific morality-related follower characteristics, which in turn affects follower behavior. To illustrate, a tremendous amount of research has argued that ethical leadership evokes moral follower behavior through general social exchange mechanisms such as the quality of the leadermember exchange relationship (e.g., Hansen et al. 2013; Walumbwa et al. 2011). Only recently have initial attempts been made to consider specific moral psychological mechanisms such as moral attentiveness (van Gils et al. 2015a, b) or moral efficacy (Lee et al. 2017) to explain work-related follower pro-social behavior. While other endeavors have started to illuminate followers' moral identity as a consequence of perceived ethical leadership, these studies have not been expanded to encompass actual work outcomes (Zhu et al. 2016). We not only provide this extension but also seek to build on the understanding of the moral essence of ethical leadership by drawing on an identity framework to outline how (through moral identity) and when (under conditions of high leader group prototypicality) leaders affect follower pro-social behavior at work.

\section{Follower Moral Identity as a Mediator Between Perceived Ethical Leadership and OCB}

Recognizing that employees' answers to the "who am I" questions (Thoits 1992) are pivotal for understanding prosocial behavior at work, scholars have become increasingly interested in the dynamic nature of employees' identity and the complex processes through which self-definitions change in leader-follower relationships (Epitropaki et al. 2017; Welbourne and Paterson 2017). Building on the idea that different identity aspects are activated by context (Lord et al. 1999), a follower's working self-concept refers to the current salient portion of self-concepts that guide actions (Epitropaki et al. 2017). Thus, it is argued that subordinates' moral identity can be a more or less activated sub-component of the working self that includes the moral values employees consider to be important and desirable (Aquino and Reed 2002; Stets and Carter 2012). In other words, the self-attributed importance of moral values may vary between contexts that provide different levels of salience to it. Furthermore, identity theory (Burke and Stets 2009; Stryker and Burke 2000) suggests that the general content of an individual's self-concepts can change over time. Hence, an individual's moral identity, while somewhat stable, may develop across adolescence (Jennings et al. 2015; Krettenauer and Hertz 2015) and change as a result of environmental stimuli such as being exposed to an ethical leader (Lord and Brown 2004; Shao et al. 2008; Zhu 2008; Zhu et al. 2016).

To understand the activated identity components in an individual's working self-concept, processes of identity salience and priming are central (Lord et al. 1999). On the one hand, ethical leaders may increase followers' immediate self-importance of moral values through highly visible signals. This can be the case, for instance, when the leader makes a visible ethical decision in a difficult situation where business and moral goals contradict each other. Yet, such rather obvious moral cues might be rare in daily work life. Therefore, on the other hand, ethical leaders may also influence follower moral identity by continually providing (low-key) ethical cues in daily settings (Piccolo et al. 2010). Ethical leaders may talk about moral values, discuss ethical standards, and provide ethical mentoring, thus making it likely that followers internalize these ethical messages. Furthermore, ethical leaders position ethical consideration firmly as a readily available norm at the workplace. Such (informal) characteristics of the work environment have been shown to possess strong identity consequences for individuals as they shape their expectations and beliefs about what is right or wrong (Grotevant 1987; Shao et al. 2008). While these low-key moral messages of ethical leaders can take some time to elevate the moral aspects of follower moral identity, initial evidence 
from the field indeed indicates that ethical leadership and follower moral identity might be connected (Zhu et al. 2016). To summarize, followers' concept of who they are, so we argue, may become more morally grounded through the (low- or high-key) moral signals of their ethical leader.

A highly salient moral identity has motivational power for individuals' actions because individuals aim to act in line with their self-concept (Blasi 1984; Van Quaquebeke et al. 2017). Herein lies the reason to ultimately expect positive effects of perceived ethical leadership on followers' work behavior: It increases their moral identity (salience). Moral identity has been linked to an expanded circle of moral regard (Reed and Aquino 2003), which means that individuals with a high moral identity tend to help other people (humanity orientation). This directly relates to aspects of OCB individual, such as supporting colleagues inside or outside one's work group without being asked. Furthermore, individuals led by ethical leaders who emphasize the importance of behavior benefiting the organization (OCB organizational) might act in line with this activated moral concern such that they are more likely to show voluntary pro-organizational behavior (Mo and Shi 2017; Shin 2012). Summarizing the arguments above, we conceptualize followers' moral identity as a mediator-the process by which ethical leadership influences OCB. In other words, we propose that employees' perceptions of ethical leadership affect their moral identity (i.e., the "being" side), which, in turn, guides their ethical behavior (the "doing" side of moral identity) — in our case, OCB. Thus, we propose:

Hypothesis 1 Follower moral identity mediates the positive relationship between perceived ethical leadership and (individual and organizational) follower OCB.

\section{The Moderating Role of Leader Group Prototypicality}

The first part of our argument is that ethical leadership produces positive follower behavior (such as OCB) through influencing followers' moral identity. However, bolstering the process rationale may not only be done via directly investigations of the mediator, but also by exploring meaningful moderators, i.e., conditions that act as "switches" to attenuate the main relationship (Spencer et al. 2005). Given our identity theorizing, we turn to perceived leader group prototypically as an identity-relevant feature in leader-follower relationships.

Leader group prototypicality describes the extent to which individuals perceive a leader to represent the group and embody the group identity (Hogg 2001; van Knippenberg 2011; van Knippenberg and Hogg 2003). Specifically, the social identity model of leadership effectiveness
(Hogg 2001; van Knippenberg 2011) argues that group membership carries identity implications for individuals, helping them to define who they are and develop a shared mindset about beliefs and values with other group members. Furthermore, groups have a normative influence on employees, affecting what group members perceive as appropriate and desirable (Abrams and Hogg 1990; Turner et al. 1987). Research by Mussweiler and Bodenhausen (2002) provides an additional angle by showing that individuals tend to align their self-concepts with those of ingroup members but contrast the same evaluations with those of out-group members. Therefore, it follows that leaders are more effective at speaking to followers' identity, and in extension their behavior, when they are perceived as group prototypical-that is, they represent what is group-normative (Hogg 2001; van Knippenberg 2011; van Knippenberg and Hogg 2003).

In line with these theoretical propositions, recent studies have shown that group prototypical leaders are indeed more effective at guiding and motivating followers than non-group prototypical leaders (Pierro et al. 2005; van Knippenberg 2011). Importantly, their in-group status also allows them more leeway in gaining support from their followers (Giessner et al. 2009; Graf et al. 2012). As such, (new) ethical norms propagated by them are also not easily dismissed but likely taken more serious than when presented by an out-group or anti-group prototypical leader. We therefore argue that ethical leaders, who are perceived as group prototypical, exhibit a stronger influence over followers' moral identity and subsequent behavior than leaders whose group prototypicality is perceived to be low. Stated formally, we propose that the indirect effect of perceived ethical leadership on OCB through follower moral identity, as stated in Hypothesis 1, is qualified by the perceived leader's group prototypicality:

Hypothesis 2 Perceived leader group prototypicality moderates the positive effect of perceived ethical leadership on OCB through follower moral identity such that the relationship is stronger for leaders perceived to be high in group prototypicality (compared to leaders perceived to be low in group prototypicality).

\section{Study 1}

\section{Methods}

\section{Pilot Study}

To establish the experimental paradigm, we recruited 106 participants from the USA (mean age $=36.33$ years, $\mathrm{SD}=9.88 ; 34.9$ females) using TurkPrime (Litman et al. 
2017) for a financial compensation of USD 0.80. Such channels allow researchers to recruit diverse samples and have been shown to deliver very acceptable data quality for academic research (Buhrmester et al. 2011; Casler et al. 2013). We randomly assigned the participants to one of four scenarios $(2 \times 2$ between-subject factorial design $)$ featuring a pre-prepared vignette. Such vignettes have proved to be as effective as laboratory experiments at evoking responses (Robinson and Clore 2001). In each vignette, participants were asked to imagine a (genderneutral) supervisor (Alex) as the leader of their work team. The leader descriptions contained our manipulations. The first factor varied the degree of ethical leadership (low vs. high), while the second factor varied leader group prototypicality (low vs. high). The leader descriptions were based on the scale items for ethical leadership (Brown et al. 2005; as employed by van Gils et al. 2015a, b) and leader group prototypicality (Giessner et al. 2013; see Appendix A for the scenario texts).

Participants read the vignette and were asked to imagine working for the described leader as vividly as possible. We then asked them so describe what it would be like to work for this supervisor, followed by two manipulation check questions. Specifically, we asked participants to indicate on a seven-point Likert scale to what extend they think Alex is an ethical leader and to what extend they think Alex is typical for the team, i.e., embodies what the teams stands for $(1=$ not at all, $7=$ very much $)$.

We conducted two one-way ANOVAs with the manipulation check items as the dependent variables. The first ANOVA analysis revealed that participants in the high ethical leadership condition rated the leader as more ethical than participants in the low ethical leadership condition, $F(1,104)=363.47, p<.001$. The effect for the leader group prototypicality condition on the ethical leadership manipulation was not significant, $F(1,104)=2.30$, $p=.13$. The second one-way ANOVA with the manipulation check item for leader group prototypicality as a dependent variable indicated that participants in the high leader group prototypicality condition rated the leader as more group prototypical than those in the low leader group prototypicality condition, $F(1,104)=92.24, p<.01$. The effect for the ethical leadership condition on the leader group prototypicality manipulation was not significant, $F(1,104)=1.21, p=.27$. Hence, the devised manipulations seem to work as intended.

\section{Sample and Procedure}

For the actual scenario experiment, we recruited a total of 170 individuals via the online platform Mechanical Turk (MTurk). Participants received USD 1.00 for completing the questionnaire. Informed consent was obtained from all individual participants included in the study. We subsequently randomly assigned the participants to one of the four scenarios described in the pilot study $(2 \times 2$ between-subject factorial design). Participants read the vignette and were asked to imagine working for the described leader as vividly as possible. To foster participants' cognitive elaboration, participants had to write a short story about what they thought working with that supervisor would be like (cf., Bhal and Dadhich 2011; van Gils et al. 2015a, b). Following this task, participants completed our questionnaire containing the measures of moral identity, OCB as well as demographic information. Specifically, we put the scales in the hypothetical context of the leader described in the vignette by asking, "When working with Alex as my supervisor, I would be ... [e.g., untruthful...truthful]."

To identify and remove participants who did not follow the instructions and selected random answers, we used instruction manipulation checks (IMCs) in the form of three checker items (e.g., "Please mark the item at 'somewhat agree"). These IMCs have proved to be effective at identifying and eliminating participants who do not provide legitimate responses (Oppenheimer et al. 2009). For this study, we excluded ten participants who did not answer these IMCs correctly. We also removed the data of 22 individuals who participated more than once (as indicated by their IP address). Our analysis is therefore based on the completed questionnaires of 138 participants (42.8\% females; average age 36.52 years, $S D=10.75$ ). Participants were living in the USA and working in various industries, with the most highly represented sectors being information technology (16.7\% of participants), health care $(13.8 \%)$, and the public sector (13\%).

\section{Measures}

Moral identity was measured with 12 items from Stets and Carter (2012; an elaboration on the original scale of Aquino and Reed 2002; Stets and Carter 2006; Walker and Hennig 2004). Cronbach's alpha for the scale was $\alpha=.90$. Respondents received a list of bipolar characteristics that capture two sub-facets, moral justice (e.g., honest/dishonest, untruthful/truthful, principled/unprincipled) and moral care (e.g., caring/uncaring, compassionate/hardhearted, selfish/selfless). These facets generally correlate highly and are thus considered together to provide a complete picture of moral identity (Stets and Carter 2012). Participants had to think about what kind of person they think they are for each pair of characteristics and place themselves on a fivepoint continuum between the two contradictory characteristics $(1=$ agreement with one characteristic, $3=$ between the two characteristics; $5=$ agreement with the other characteristic). The semantic differential technique 
constitutes a typical approach to capturing the meaning of many identities that can all separately contribute to an individual's working self-concept (Burke and Stets 2009; Osgood et al. 1957). This measurement approach considers the subjective meanings people ascribe to their current selfconcept and has been successfully used before to measure a range of different identity aspects (e.g., Carter 2013, see also Stets and Serpe 2013).

We assessed OCB with 14 items developed by Williams and Anderson (1991). Participants were asked to think of the vignette again and describe how they would behave if they worked for a supervisor like Alex. The scale consists of two sub-dimensions (OCB individual and organizational), each featuring seven items measured with seven-point Likert scales $(1=$ strongly disagree, 7 = strongly agree). Firstly, individual-oriented OCB refers to behaviors relating to coworkers; a sample item is "When working for a supervisor like Alex, I would help others who have heavy workloads." Secondly, organization-directed OCB characterizes general actions at work that support or harm organizational goal attainment; a sample item is "When working for a supervisor like Alex, I would conserve and protect organizational property." Cronbach's alphas for the two sub-scales were $\alpha=.90$ and $\alpha=.85$.

\section{Results}

Table 1 shows the study variables' means and standard deviations. Prior to testing the hypotheses, we conducted a confirmatory factor analysis (CFA, robust MLM estimator) with Mplus (Muthén and Muthén 2012) to estimate the distinctiveness of the assessed variables (follower moral identity, OCB individual, and OCB organizational). The correlated three-factor solution (with moral identity as a second-order factor of the two sub-facets, moral care and moral justice) fit the data well (Vandenberg and Lance 2000), $\quad$ RMSEA $=0.07, \quad$ CFI $=0.90, \quad$ SRMR $=0.07$. These fit indices clearly outperformed a one-factor model (RMSEA $=0.13, \mathrm{CFI}=0.67, \mathrm{SRMR}=0.10)$. To continue with our hypothesis testing, we used the regressionbased PROCESS macro for SPSS (Hayes 2013, 2015).

\section{Ethical Leadership, OCB, and Follower Moral Identity}

In line with Hypothesis 1, the indirect effect of ethical leadership through follower moral identity on OCB was significant for OCB individual $(b=.31$; CI .09-.55) and for OCB organizational ( $b=.28$; CI .07-.50). There was no remaining significant direct effect on OCB individual $(b=-.05 ; \mathrm{CI}-.35$ to .25$)$ and OCB organizational $(b=-.04 ; \mathrm{CI}-.32$ to .24$)$.

\section{Moderated Mediation}

As depicted in Table 2, the interaction effect between the ethical leadership condition and the leader group prototypicality condition on follower moral identity was significant $(b=.68$, CI .14-1.22). Figure 2 depicts the interaction effect between ethical leadership and leader group prototypicality on follower moral identity.

To test Hypothesis 2, we calculated a moderated mediation model following the procedure recently developed by Hayes (2015). This formal test of linear moderated mediation in path analysis is based on an interval estimate of an index of moderated mediation, which is a function linking the indirect effect of an independent variable to a moderator (for the theoretical rationale, cf. Hayes 2015). Only a single inferential test is necessary to determine whether a test of moderated mediation is supported, which occurs if the bootstrapping interval of the moderated mediation index does not include zero. In line with Hypothesis 2, the moderated mediation index was positive for both OCB individual $(\omega=.55$; CI .18-1.04) and OCB organizational $(\omega=.50 ; \mathrm{CI} .13-.95)$. Since the bootstrapping interval did not include zero, the moderated mediation index can be interpreted as significant. The moderated mediation effect remained significant even when including control variables such as age and gender $(\omega=.54$; CI .18-.97 for OCB individual and $\omega=.48$; CI .14-.91 for OCB organizational), which points to a certain robustness of the effect.

As expected, the conditional indirect effect of perceived ethical leadership on OCB individual through follower moral identity at different values of the moderator ( $1=$ low leader group prototypicality condition; $2=$ high
Table 1 Study 1: descriptive statistics and correlations of study variables (Cronbach's alpha in brackets, where applicable)

\begin{tabular}{|c|c|c|c|c|c|c|c|}
\hline Variable & $M$ & SD & (1) & (2) & (3) & (4) & $(5)$ \\
\hline 1. Ethical leadership ${ }^{a}$ & 1.49 & 0.50 & & & & & \\
\hline 2. Leader group prototypicality ${ }^{a}$ & 1.53 & 0.50 & & & & & \\
\hline 3. Follower moral identity & 4.09 & 0.38 & $.23 * *$ & .03 & $(.94)$ & & \\
\hline 4. OCB individual & 5.27 & 1.10 & .12 & -.04 & $.61 * *$ & $(.90)$ & \\
\hline 5. OCB organizational & 5.75 & 1.00 & .12 & -.03 & $.61 * *$ & $.61 * *$ & $(.85)$ \\
\hline
\end{tabular}


Table 2 Study 1: Unstandardized OLS regression coefficients (standard errors in brackets) with confidence intervals (CI)

\begin{tabular}{|c|c|c|c|c|c|c|}
\hline & \multicolumn{2}{|c|}{ Moral identity $(M)$} & \multicolumn{2}{|c|}{ OCB individual $\left(Y_{1}\right)$} & \multicolumn{2}{|c|}{ OCB organizational $\left(Y_{2}\right)$} \\
\hline & $b$ & $95 \% \mathrm{CI}$ & $b$ & $95 \% \mathrm{CI}$ & $b$ & $95 \% \mathrm{CI}$ \\
\hline Ethical leadership $^{\mathrm{a}}(X)$ & $0.39 * *(0.14)$ & $0.12,0.66$ & $-0.05(0.15)$ & $-0.35,0.25$ & $-0.04(0.14)$ & $-0.32,0.24$ \\
\hline Leader group prot. $^{\mathrm{a}}(W)$ & $0.09(0.14)$ & $-0.18,0.36$ & & & & \\
\hline$X \times W$ & $0.68 *(0.27)$ & $0.14,1.22$ & & & & \\
\hline \multirow[t]{3}{*}{ Follower moral identity $(M)$} & & & $0.81 * * *(0.09)$ & $0.63,1.00$ & $0.73 * * *(0.09)$ & $0.56,0.90$ \\
\hline & \multicolumn{2}{|l|}{$R^{2}=.10$} & \multicolumn{2}{|l|}{$R^{2}=.37$} & \multicolumn{2}{|l|}{$R^{2}=.36$} \\
\hline & \multicolumn{2}{|c|}{$F(3,134)=4.88^{* * *}$} & \multicolumn{2}{|c|}{$F(2,135)=39.70 * * *$} & \multicolumn{2}{|c|}{$F(2,135)=38.38 * * *$} \\
\hline
\end{tabular}

$* p<.05 ; * * p<.01 ; * * * p<.001$

${ }^{\text {a }}$ Conditions: 1 = low; 2 = high; $N=138$

Fig. 2 Study 1: Interaction effect between ethical leadership and leader group prototypicality on follower moral identity

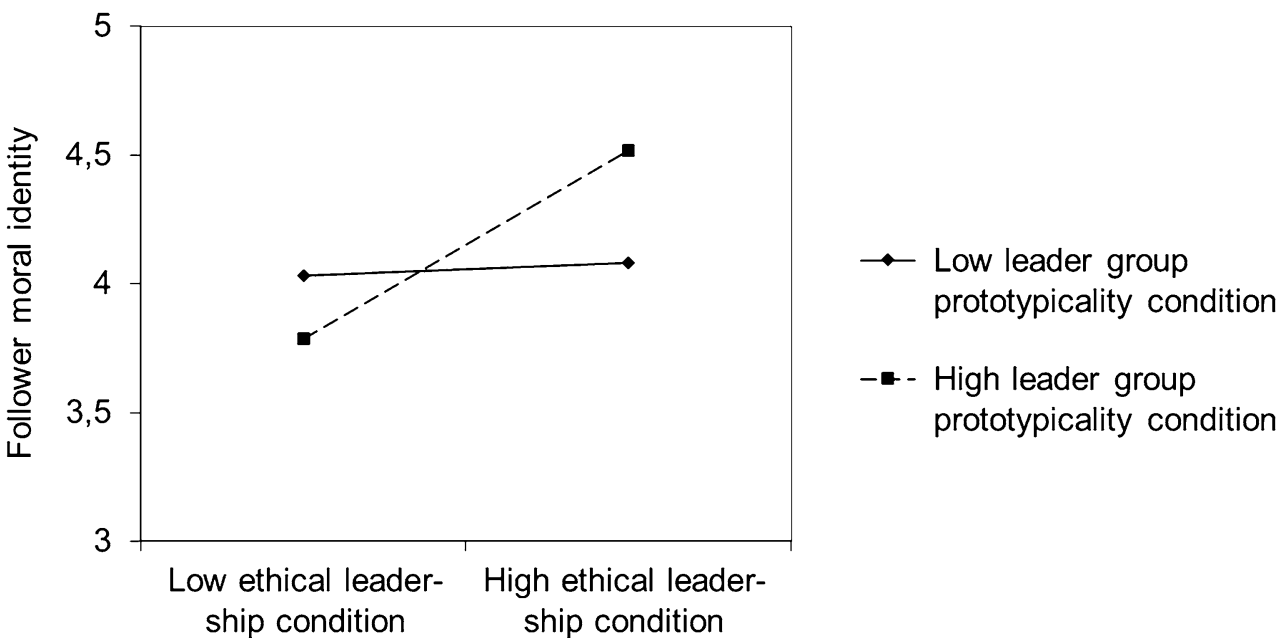

leader group prototypicality condition) was significant in the high prototypicality condition ( $b=.58$; CI .28-.93) but not in the low condition ( $b=.03$; CI -.29 to .29; Table 3 ). For OCB organizational, the conditional indirect effect was also significant in the high group prototypicality condition ( $b=.52$; CI .24-.88) but not in the low condition ( $b=.02$; CI -.25-.26; Table 3).

\section{Study 2}

While Study 1 was able to establish causality using a "clean" empirical design, it may have been limited by some degree of demand characteristic. Although demand characteristics cannot really account for the uncovered interactions, we nevertheless sought to replicate our findings in the field, which has the added benefit of providing external validity.

Moreover, the dichotomous nature of the experimental manipulation in Study 1 only allows to observe that the mediation is present at high leader group prototypicality but not at low leader group prototypicality. As such, we do not know where the tipping point of significance may lie. Because of the continuous nature of the variables in the field, we also used this second study to more exactly identify the region of perceived leader group prototypicality at which perceived ethical leadership may cease to exhibit an effect on follower moral identity and in its extension on follower OCB.
Table 3 Study 1: Conditional indirect effects of ethical leadership on OCB through follower moral identity in both moderator (leader group prototypicality) conditions $(1=$ low, $2=$ high $)$

\begin{tabular}{llll}
\hline Outcome & Leader group prototypicality & Effect & $95 \%$ CI \\
\hline OCB individual & 1.00 & 0.03 & $-0.29,0.29$ \\
& 2.00 & 0.58 & $0.28,0.93$ \\
OCB organizational & 1.00 & 0.02 & $-0.25,0.26$ \\
& 2.00 & 0.52 & $0.24,0.88$ \\
\hline
\end{tabular}




\section{Methods}

\section{Sample and Procedure}

To recruit a diverse sample for our field study and to increase the confidence in our findings, we decided to use a different online data collection platform than in Study 1. Particularly, building on the idea that the moral identity mechanism is a general process through which leaders influence their followers, we sought to recruit a sample of employees working in different industries, organizations, and occupations in industrialized Western countries. Against this background, we decided to use CrowdFlower to collect 342 questionnaires and paid USD 0.70 to participants for completing the survey. CrowdFlower partners with a multitude of labor pools to increase the diversity of their workforce and at the same time ensure data quality through the strict control and training of their workers (Peer et al. 2017). We excluded 52 people who did not pass our IMCs and 64 people who participated more than once (as indicated by their IP address). Our final sample consisted of 225 participants (54.2\% females; average age 38.54 years, $\mathrm{SD}=10.97$ ). Informed consent was obtained from all individual participants included in the study. $45.3 \%$ of our sample lived in Europe, $35.6 \%$ in the USA, $16.4 \%$ in Canada, and $2.7 \%$ resided in other countries. $14 \%$ of the sample was employed in the secondary sector (i.e., goodsproducing industries) and $84.4 \%$ of the participants worked in the tertiary sector (i.e., service-providing industries) with the most highly represented industries being information technology $(15.6 \%)$, the public sector $(13.8 \%)$, and health care (12\%). On average, respondents had worked with their current supervisor for 4.45 years $(\mathrm{SD}=4.68)$.

\section{Measures}

We assessed perceived ethical leadership with the ten-item scale developed by Brown et al. (2005). Sample items include: "My supervisor disciplines employees who violate ethical standards" and "My supervisor defines success not just by results, but also by the way that they are obtained." Answers were given on a seven-point Likert scale ranging from 1 (strongly disagree) to 7 (strongly agree). Cronbach's alpha for the scale was $\alpha=.95$.

To operationalize leader group prototypicality, we used six items from Giessner et al. (2013). Participants indicated their agreement on a seven-point Likert scale $(1=$ strongly disagree, $7=$ strongly agree). Sample items include: "My supervisor has much in common with the members of our team" and "My supervisor represents what is characteristic about our team" $(\alpha=.97)$.

Moral identity was measured with 12 items from Stets and Carter (2012; see Study 1). Respondents had to place themselves along a continuum between two contradictory characteristics $(1=$ agreement with one characteristic, $3=$ between the two characteristics; $5=$ agreement with the opposing characteristic). Cronbach's alpha for the scale was $\alpha=.88$.

We operationalized OCB with 14 items developed by Williams and Anderson (1991). As in Study 1, OCB individual and $\mathrm{OCB}$ organizational were assessed with seven items each. Cronbach's alphas for the two sub-scales were $\alpha=.86$ and $\alpha=.76$.

\section{Results}

We followed the same procedure as in Study 1 and used the PROCESS macro (including mean-centered predictor and moderator variable) to calculate our models. Table 4 shows the study variables' means, correlations, and standard deviations.

\section{Confirmatory Factor Analysis}

Using the same procedure as in Study 1, we conducted a CFA to ensure that the surveyed measures (perceived ethical leadership, follower moral identity, leader group prototypicality, OCB individual, OCB organizational) were sufficiently distinct from each other to continue our hypothesis testing. The correlated five-factor solution (with moral identity as a second-order factor of the two subfacets, moral care and moral justice) fit the data well $(\mathrm{RMSEA}=0.05, \mathrm{CFI}=0.95, \mathrm{SRMR}=0.06)$ and clearly outperformed the one-factor baseline model $($ RMSEA $=0.14, \mathrm{CFI}=0.66, \mathrm{SRMR}=0.16)$.

Additionally, we calculated the post hoc Harman singlefactor test (Podsakoff and Organ 1986) to determine whether common method bias might potentially confound the interpretation of the results. This is the case if (1) one general factor accounts for the majority of the covariance among the variables or (2) a single factor emerges from a factor analysis. Our analysis clearly revealed that neither one general factor nor the first (largest) factor accounted for the majority of the variance (12\%), thus indicating that this type of bias was not a concern.

\section{Perceived Ethical Leadership, OCB, and Follower Moral Identity}

Both OCB individual $\left(r=.20^{* *}\right)$ and OCB organizational $\left(r=.16^{*}\right)$ were positively correlated with perceived ethical leadership. Follower moral identity positively correlated with $\mathrm{OCB}$ individual $\left(r=.41^{* *}\right)$ and $\mathrm{OCB}$ organizational $(r=.59 * *)$. The indirect effect of perceived ethical leadership on OCB through follower moral identity was significant for both OCB individual $(b=.07$; CI $.02-$ 
Table 4 Study 2: Descriptive statistics and correlations of study variables (Cronbach's alpha in brackets)

\begin{tabular}{llllllll}
\hline Variable & $M$ & SD & $(1)$ & $(2)$ & (3) & (4) & (5) \\
\hline 1. Ethical leadership & 4.89 & 1.26 & $(.95)$ & & & & \\
2. Leader group prototypicality & 4.74 & 1.48 & $.79^{* *}$ & $(.97)$ & & & \\
3. Follower moral identity & 4.16 & 0.59 & $.21^{* *}$ & $.18^{* *}$ & $(.88)$ & & \\
4. OCB individual & 5.11 & 1.10 & $.20^{* *}$ & $.18^{* *}$ & $.41^{* *}$ & $(.86)$ & \\
5. OCB organizational & 5.50 & 0.97 & $.16^{*}$ & $.16^{*}$ & $.59^{* *}$ & $.46^{* *}$ & $(.76)$ \\
\hline$N=225$ & & & & & & & \\
$* p<.05 ; * * p<.01$ (two-tailed) & & & & & & &
\end{tabular}

$.13)$ and OCB organizational $(b=.09$; CI .03-.16), which supports Hypothesis 1. As already observed in Study 1, the remaining direct effect between perceived ethical leadership and OCB individual $(b=.10 ;$ CI -.00 to .21 , $p=.06)$ and OCB organizational $(b=.06$; CI .03-.09, $p=.46$ ) was not significant (Table 5).

\section{Moderated Mediation}

To test whether leader group prototypicality moderates the identified mediation effect (Hypothesis 2), we calculated a moderated mediation index. The moderated mediation index was positive, and the bootstrapping interval did not include zero for either OCB individual $(\omega=.06$; CI .03$.09)$ or OCB organizational ( $\omega=.08$; CI .05-.11), which provides support for our hypothesis. Figure 3 depicts the interaction effect between perceptions of ethical leadership and leader group prototypicality on follower moral identity. As in Study 1, the moderated mediation effect was robust against the inclusion of control variables such as age and gender $(\omega=.04$; CI $.02-.08$ for OCB individual and $\omega=.06$; CI .03-.09 for OCB organizational).

Next, we calculated the conditional indirect effect of perceived ethical leadership on OCB individual through follower moral identity at three levels of leader group prototypicality, namely the mean value, a high value $(+1$ $\mathrm{SD})$, and a low value $(-1 \mathrm{SD})$. The conditional indirect effect of perceived ethical leadership on OCB individual was significant at the high $(b=.19$; CI .08-.32) and the mean value ( $b=.10$; CI .03-.19) of leader group prototypicality but not at the low value $(b=.02 ; \mathrm{CI}-.06$ to .09 ; Table 6). The value of perceived group prototypicality at which the indirect effect for OCB individual became significant was 4.30 , which is slightly below the mean of 4.74 ( $\mathrm{SD}=1.48$ ). Similarly, the conditional indirect effect of perceived ethical leadership on OCB organizational was significant at the high $(b=.25 ; \mathrm{CI} .12-.39)$ and the mean value ( $b=.13$; CI .04-.25) of leader group prototypicality but not at the low value ( $b=.02$; CI $-.08-.11$; Table 6$)$. The value of perceived group prototypicality at which the indirect effect for OCB organizational became significant was 4.21 .

\section{Discussion}

The purpose of this research was to advance the literature on ethical leadership by investigating the moral process through which followers' perceptions of ethical leadership influence broader outcomes. As such, we are among the first to use an identity perspective (Zhu et al. 2016) to explore the psychological processes via which ethical leadership influences OCB (Brown and Treviño 2006; $\mathrm{Ng}$ and Feldman 2015). To substantiate our identity reasoning, we performed two tests of the mechanism (Jacoby and Sassenberg 2011; Spencer et al. 2005), namely follower moral identity as a mediator and perceived leader group prototypicality as a moderator. As hypothesized, follower

Table 5 Study 2: Unstandardized OLS regression coefficients (standard errors in brackets) with confidence intervals (CI)

\begin{tabular}{|c|c|c|c|c|c|c|}
\hline & \multicolumn{2}{|c|}{ Moral identity $(M)$} & \multicolumn{2}{|c|}{ OCB individual $\left(Y_{1}\right)$} & \multicolumn{2}{|c|}{ OCB organizational $\left(Y_{2}\right)$} \\
\hline & $b$ & $95 \% \mathrm{CI}$ & $b$ & $95 \% \mathrm{CI}$ & $b$ & $95 \% \mathrm{CI}$ \\
\hline Ethical leadership $(X)$ & $0.14 * *(0.05)$ & $0.04,0.24$ & $0.10(0.05)$ & $-0.00,0.21$ & $0.03(0.04)$ & $-0.05,0.12$ \\
\hline Leader group prot. $(W)$ & $0.04(0.04)$ & $-0.04,0.12$ & & & & \\
\hline$X \times W$ & $0.08 * * *(0.02)$ & $0.05,0.11$ & & & & \\
\hline \multirow[t]{3}{*}{ Follower moral identity $(M)$} & & & $0.72 * * *(0.12)$ & $0.49,0.95$ & $0.95 * * *(0.09)$ & $0.77,1.13$ \\
\hline & \multicolumn{2}{|l|}{$R^{2}=.14$} & \multicolumn{2}{|l|}{$R^{2}=.18$} & \multicolumn{2}{|l|}{$R^{2}=.34$} \\
\hline & \multicolumn{2}{|c|}{$F(3,221)=11.70 * * *$} & \multicolumn{2}{|c|}{$F(2,222)=24.85^{* * *}$} & \multicolumn{2}{|c|}{$F(2,222)=58.10 * * *$} \\
\hline
\end{tabular}

$N=225$

$* p<.05 ; * * p<.01$; *** $p<.001$ 
Fig. 3 Study 2: Interaction effect between perceptions of ethical leadership and leader group prototypicality on follower moral identity

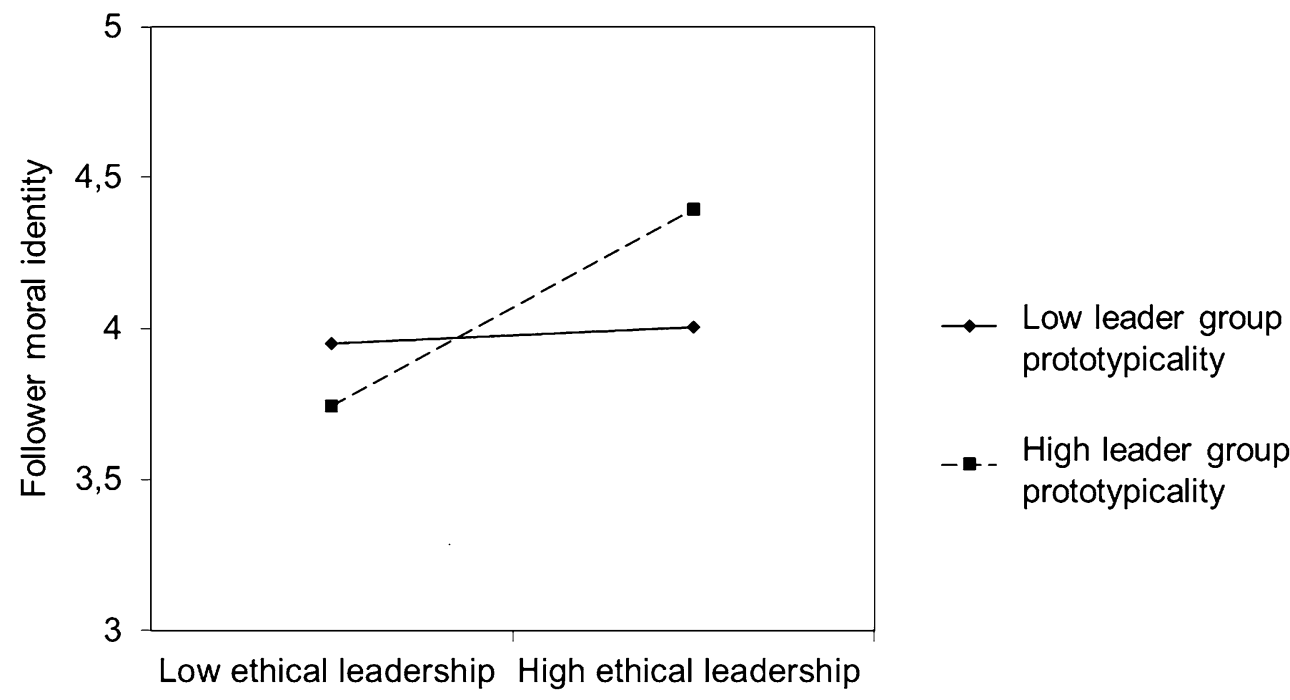

Table 6 Study 2: Conditional indirect effects of perceived ethical leadership on OCB through follower moral identity at different values (mean, mean \pm one SD) of the moderator "perceived leader group prototypicality"

\begin{tabular}{llll}
\hline Outcome & Leader group prototypicality & Effect & $95 \%$ CI \\
\hline OCB individual & 3.26 & 0.02 & $-0.06,0.09$ \\
& 4.74 & 0.10 & $0.03,0.19$ \\
OCB organizational & 6.22 & 0.19 & $0.08,0.32$ \\
& 3.26 & 0.02 & $-0.08,0.11$ \\
& 4.74 & 0.13 & $0.04,0.25$ \\
& 6.22 & 0.25 & $0.12,0.39$ \\
\hline
\end{tabular}

moral identity mediated the relationship between perceived ethical leadership and both types of OCB (individual-directed and organization-directed). Meanwhile, perceived leader group prototypicality moderated the indirect effect of ethical leadership on OCB through follower moral identity, such that perceived ethical leadership more positively influenced followers' moral self-concept and subsequent OCB if leaders were perceived as highly group prototypical. Together, these findings soundly underpin the relevance of (moral) identity in explaining the effect of ethical leadership on follower behavior at work.

The major methodological strengths of this research include the application of different methodologies (a scenario experiment and a field study) and the use of mediation and moderation to meaningfully substantiate the identity process. The use of different methodologies increases our confidence in the findings, as the strengths of one study can compensate for the weaknesses of the other. For instance, the experimental design allowed us to systematically manipulate the constructs of interest, while the field study showed that our conceptual model holds true in a day-to-day work context where subordinates have been working with their supervisor for an extended period of time. Lastly, the complete model also replicated in two different samples. Together, this corroborates trust in the findings.

\section{Theoretical Implications and Future Research}

This research has several implications for future theorizing and empirical work in the ethical leadership field. Firstly, our results indicate that followers' moral identity can be altered by strong ethical leaders. As such, our finding contributes to the debate about flexibility versus stability of moral identity across people's life spans (Krettenauer and Hertz 2015; Leavitt et al. 2015). Although it was beyond the scope of the study, it would be interesting to determine whether an ethical leader's influence over a follower's moral identity persists over time-for instance, when an employee moves to a new work group or is promoted into a leadership position (Zhu et al. 2016). Furthermore, researchers might want to investigate whether "authentic" ethical leaders (i.e., those with also a strong internalized moral identity) are more effective at influencing followers' moral identity than leaders displaying ethical leadership without really meaning it (i.e., those who publicly express moral actions only to reach a certain goal; cf. Den Hartog and Belschak 2012). In addition, if moral identity is pliable, then it is possible that coworkers' moral identity could also affect employees' moral identity and complement or counteract the (in-group) leader's influence on followers' self-concept. 
Secondly, while it is in the nature of our field survey that it cannot distinguish between cause and effect, the findings of our experimental study provide unambiguous evidence for a causal link between ethical leadership and followers' moral identity. The results overall support the assumptions inherent to "upper-echelon" approaches-namely, that higher-status leaders exert a significant top-down influence on the organization (Hambrick and Mason 1984). Notably though, while we established this direction of influence through our experimental design in Study 1, it is possible that the causality could also work in the opposite direction. In other words, followers' moral identity could influence leaders' moral identity and, by extension, their ethical behavior. Indeed, an experiment by Tee, Ashkanasy, and Paulsen (2013) provides support for a reverse transfer of followers' moods to their leader's mood, which can ultimately have an impact on the leader's task performance. Similarly, Hsee et al. (1990) found that powerful individuals, such as teachers, were prone to mirror subordinates' feelings. In a switch of perspectives unusual for the leadership field, future research may want to examine whether this reverse causality also occurs in organizations. For instance, scholars could analyze whether leaders' perceptions of ethical followership ultimately have an impact on the leaders' moral identity and, consequently, on their ethical leadership behavior. Furthermore, it could be of interest to investigate if these effects are stronger when high power (compared to low power) team members are group prototypical or how these effects change depending on the degree of interdependence between leaders and followers (Gerpott et al. in press).

Thirdly, we uncovered that leaders must be perceived as being representative of their groups in order to influence followers' ethical characteristics and subsequent behaviors effectively. Put differently and considering the finer-grained analyses of Study 2, for ethical leadership to affect follower moral identity and by extension their OCB, it seems necessary that leaders are not perceived to be anti-group prototypical. Indeed, followers may not automatically undergo changes in their moral identity simply from perceiving ethical leadership; rather, their "buy in" depends on their evaluation of how much the leader represents the group. In this respect, future research may be able to further nuance the moderating role of leader group prototypicality, perhaps by contrasting it with other socio-cognitive processes as well. For example, future scholars could determine the relative importance of group prototypicality versus leader prototypicality (Hains et al. 1997). In contrast to group prototypicality, leader prototypicality captures the extent to which a leader matches a follower's stereotypical concept of an ideal leader (i.e., their implicit leadership theories; Junker and van Dick 2014; Van Quaquebeke et al. 2014a). The central question would be whether ethical leaders are better served by representing the group ideal or the leader ideal, or whether an interaction might exist. In a similar vein, leader group prototypicality may be complemented or even substituted by leaders' group identification, which refers to their ability to project a sense of "we" and "us" as part of their self-concept (Steffens et al. 2015).

Lastly, with regard to group prototypicality, future research could examine whether specific group values are more effective at reinforcing the moral message of ethical leadership. Most research in the business and management domain has focused on ideal (approach-oriented) values that emphasize desired end-states (Van Quaquebeke et al. 2014b). However, the human motivation literature suggests that individuals are driven by two forces: approach and avoidance motivation. By implication, a leader's counterideal (avoidance-oriented) values could also increase followers' perceptions of leader group prototypicality (Schuh et al. 2016; Van Quaquebeke et al. 2014a, b). In line with the idea that "bad is stronger than good" (Baumeister et al. 2001), counter-ideal values highlighting undesirable endstates might be particularly relevant to followers' evaluations of a leader's group prototypicality. Even more so, due to their avoidance nature, a counter-ideal value group prototypicality may also resonate more with the message of ethical leadership as it too is more often than not in reference to prevention rather than reaching for the stars.

\section{Practical Implications}

Several findings from our study may be of consequence for practice. Firstly, the external recruitment of highly ethical leaders may backfire if followers do not perceive those leaders as being prototypical for their group (cf. Graf et al. 2012). Similarly, leadership training that aims to increase supervisors' ethical awareness may only be optimally effective if followers perceive the trained leader as group prototypical. Although we propose that ethical leadership is a managerial style that should be strived for as an end in itself, organizations hoping to promote OCB should not only develop leaders' ethical characteristics but also encourage ethical leaders to reflect on how well they represent their groups. To promote insight into the group prototype (i.e., followers' mental representations about a group's defining characteristics), HR departments might develop instruments, such as team workshops, to help delineate common values and a joint purpose. In an interactive setting, followers can discuss what they think is typical for their group in comparison with other relevant groups. This could have a dual effect of (1) helping leaders understand how to position themselves as more group prototypical and (2) helping group members realize the more group prototypical aspects of their leaders.

Secondly, organizations might not want to rely solely on leaders to increase followers' moral identity. As indicated 
by the high correlation between moral identity and the two types of OCB in our study, moral identity exerts a strong influence on employees' behavior in different organizational contexts (Skarlicki et al. 2016). Therefore, organizations aiming to foster more ethical employee behavior may want to appeal to employees' moral identity-both through their supervisors and beyond. For instance, fostering a general ethical climate in the organization (Ambrose et al. 2008; Schminke et al. 2005; Victor and Cullen 1988) or supporting coworkers' moral identity (Thornton and Rupp 2015) and peer leadership (Schaubroeck et al. 2016) may also represent viable ways to stimulate employees' sense of moral identity.

\section{Limitations and Future Research}

Of course, this study is not without limitations. Firstly, we exclusively measured followers' reports of OCB rather than actual behavior or third-party reports of follower behavior. While recent meta-analytical results suggest that there are valid reasons to use employees' perceptions of OCB (Carpenter et al. 2014), future research may still want to spread the outcomes into other domains, such as followers' ethical decision making when, for example, advising clients (van Gils et al. 2015a).

Secondly, we used an explicit measure of moral identity to capture the current importance of moral characteristics for participants in their self-concept (Stets and Carter 2012). This may have brought about some socially desirable answer patterns. In any case, neither the systematic variation nor the findings regarding the moderation can be explained by social desirability. Nevertheless, our measure could be compared to an implicit operationalization of moral identity that does not rely on participants' verbal reports. For instance, the implicit association test, which presents participants with various stimuli on a computer screen (e.g., TREE and TRUTHFUL), could be used to associate individuals' reaction speeds with the strength of their moral identity. In fairness, however, Hertz and Krettenauer's (2016) recent meta-analysis showed that the effect sizes of studies combining explicit measures of moral identity with behavioral observations or third-party ratings were not much lower than those of studies based on self-reported data. A different avenue for future research could be the inclusion of a traitlike moral motive measure that assesses people's relative degree of moral development or their general ethical perspective (e.g., Forsyth 1980; Gibbs et al. 1992) in addition to the moral identity measure used in the present studies. Scholars could then investigate the change effect of ethical leadership on followers' (state) moral identity while controlling for the effect of trait morality.

Thirdly, we conducted our studies using online data collection platforms. While some critics have claimed that platform workers spend much of their time participating in studies and thus might have gained experience with common experimental tasks and questionnaires (Peer et al. 2017), we have several reasons to assume that these concerns do not reduce the reliability of our findings. Firstly, a moderated mediation effect cannot be the result of an intended response pattern of the participants across studies (Van Quaquebeke et al. 2011). In other words, even if participants were familiar with our survey items and replied in a way they think is favorable to our research aim, this could increase the correlations between our study variables but at the same time severely deflate the interaction effect, making it more difficult to detect through statistical means (Siemsen et al. 2009). Secondly, we recruited participants from different platforms in Studies 1 and 2 to increase the diversity of our samples and thus the generalizability of our findings (Peer et al. 2017). Lastly, speaking against an overestimation of our effects, workers' experience with online surveys is expected to reduce (rather than increase) the effect sizes of known research findings (Chandler et al. 2015). Notably, at least our experimental design also had the advantage of being able to manipulate ethical leadership. Yet, in case future research wants to replicate our findings in an organizational setting, we suggest running a time-lagged, quasi-experimental study with teams who are assigned a new leader. Employees would provide their moral identity and OCB ratings at time 1 (i.e., before the leader joins the team) and would administer these ratings again in a follow-up study. In this second questionnaire, employees would also rate their leaders' ethical behavior and group prototypicality. If the follow-up surveys can be disseminated over time, such a design could potentially also elucidate some cross-lagged effect on the sustainability of ethical leadership on follower moral identity. Another approach may lie in the identification of suitable instrumental variables to counter endogeneity in the analyses and corroborate causality (Antonakis 2017). However, to the best of our knowledge, an optimal instrument for ethical leadership has yet to be found.

Lastly, common source bias and participants' inclination for social desirability (i.e., reporting behavior as more positive than it actually is) can indeed raise the main effect; importantly, however, it cannot explain the complexity of interaction effects observed in the experiment and the field study (Van Quaquebeke et al. 2011). If anything, common method biases actually work against finding interaction confirmed (Siemsen et al. 2009). What is equally noteworthy is that the moderating role of leader group prototypicality also held true when control variables were included. Thus, while an assumed demand characteristic may be able to explain the main effect, it is an unlikely explanation for the uncovered interaction. In addition, specifically for our field study, the Harman single-factor 
test also indicated that common method biases are not a concern.

\section{Conclusion}

As a field, leadership research has been called "curiously unformed" (Hackman and Wageman 2007, p. 43), and research on ethical leadership is no exception. Part of the problem is the difficulty in disentangling the proliferating number of leadership concepts. In our view, many of these concepts are unfortunately all too often explored only superficially and lack an investigation into their specific essences. In order to help remedy this situation, this study argued for two nested processes of identity and morality that flow from ethical leadership and closely relate to its moral essence. As such, we believe the study to be a small but meaningful step toward understanding the specific moral mechanisms that underlie the link between ethical leadership and organizational outcomes.

Funding This work was supported by the Vrije Universiteit Amsterdam and the Kühne Logistics University (no specific grant-funded by general resources available to the universities).

\section{Compliance with Ethical Standards}

Conflict of interest The authors declare that they have no conflict of interest.

Ethical Approval All procedures performed in studies involving human participants were in accordance with the ethical standards of the institutional and/or national research committee and with the 1964 Helsinki Declaration and its later amendments or comparable ethical standards.

Informed Consent Informed consent was obtained from all individual participants included in the study.

Open Access This article is distributed under the terms of the Creative Commons Attribution 4.0 International License (http://creative commons.org/licenses/by/4.0/), which permits unrestricted use, distribution, and reproduction in any medium, provided you give appropriate credit to the original author(s) and the source, provide a link to the Creative Commons license, and indicate if changes were made.

\section{Appendix}

The leader descriptions were based on the scale items of leader group prototypicality (Giessner et al. 2013) and ethical leadership (Brown et al. 2005; similarly employed by van Gils et al. 2015a, b).

\section{High Leader Group Prototypicality}

Imagine that you are working for a supervisor named Alex. Alex embodies the norms of your team and is generally a good example of the kind of people who are members of your team. Alex has much in common with the members of your team. That means, Alex generally represents what is characteristic about your team.

\section{Low Leader Group Prototypicality}

Imagine that you are working for a supervisor named Alex. Alex does not embody the norms of your team and us generally not a good example of the kind of people who are members of your team. Alex has nothing in common with the members of your team. That means, Alex does not at all represent what is characteristic about your team.

\section{High Ethical Leadership}

Alex is a supervisor who very strongly believes in doing the "right" thing in terms of ethics, without making compromises. Alex likes to be seen as a person who always makes ethical decisions. Alex consistently acts according to ethical values when making decisions. This is the reason that Alex does not tolerate any violations of ethical standards. When faced with dilemmas at work, Alex asks, "What is the right thing to do?"

\section{Low Ethical Leadership}

Alex is a supervisor who does not believe in doing the "right" thing in terms of ethics. That is why Alex often makes compromises regarding ethics. Many people will describe Alex as a person who never makes ethical decisions. Alex hardly ever acts consistently according to ethical values when making decisions. This is the reason that Alex tolerates violations of ethical standards. When faced with dilemmas at work, Alex says "Get it done by any means."

\section{References}

Abrams, D., \& Hogg, M. A. (1990). Social identification, selfcategorization and social influence. European Review of Social Psychology, 1, 195-228. doi:10.1080/14792779108401862.

Ambrose, M., Arnaud, A., \& Schminke, M. (2008). Individual moral development and ethical climate: The influence of personorganization fit on job attitudes. Journal of Business Ethics, 7, 323-333. doi:10.1007/s10551-007-9352-1.

Antonakis, J. (2017). On doing better science: From thrill of discovery to policy implications. Leadership Quarterly, 28, 5-21. doi:10.1016/j.leaqua.2017.01.006.

Aquino, K., \& Reed, A., II. (2002). The self-importance of moral identity. Journal of Personality and Social Psychology, 83, 1423-1440. doi:10.1037/0022-3514.83.6.1423.

Avey, J. B., Palanski, M., \& Walumbwa, F. (2011). When leadership goes unnoticed: The moderating role of follower self-esteem on the relationship between ethical leadership and follower 
behavior. Journal of Business Ethics, 98, 573-582. doi:10.1007/ s10551-010-0610-2.

Avey, J. B., Wernsing, T. S., \& Palanski, M. E. (2012). Exploring the process of ethical leadership: The mediating role of employee voice and psychological ownership. Journal of Business Ethics, 107, 21-34. doi:10.1007/s10551-012-1298-2.

Baumeister, R. F., Bratslavsky, E., Finkenauer, C., \& Vohs, K. D. (2001). Bad is stronger than good. Review of General Psychology, 5, 323-370. doi:10.1037/1089-2680.5.4.323.

Bhal, K., \& Dadhich, A. (2011). Impact of ethical leadership and leader-member exchange on whistle blowing: The moderating impact of the moral intensity of the issue. Journal of Business Ethics, 103, 485-496. doi:10.1007/s10551-011-0876-z.

Blasi, A. (1984). Moral identity: Its role in moral functioning. In W. M. Kurtines \& J. J. Gewirtz (Eds.), Morality, moral behavior and moral development (pp. 128-139). New York: Wiley.

Brown, M. E., \& Treviño, L. K. (2006). Ethical leadership: A review and future directions. Leadership Quarterly, 17, 595-616. doi:10.1016/j.leaqua.2006.10.004.

Brown, M. E., Treviño, L. K., \& Harrison, D. A. (2005). Ethical leadership: A social learning perspective for construct development and testing. Organizational Behavior and Human Decision Processes, 97, 117-134. doi:10.1016/j.obhdp.2005.03.002.

Buhrmester, M., Kwang, T., \& Gosling, S. D. (2011). Amazon's Mechanical Turk: A new source of inexpensive, yet high-quality, data? Perspectives on Psychological Science, 6, 3-5. doi:10. $1177 / 1745691610393980$.

Burke, P. J., \& Stets, J. E. (2009). Identity theory. New York: Oxford University Press.

Carpenter, N. C., Berry, C. M., \& Houston, L. (2014). A metaanalytic comparison of self-reported and other-reported organizational citizenship behavior. Journal of Organizational Behavior, 35, 547-574. doi:10.1002/job.1909.

Carter, M. J. (2013). Advancing identity theory: Examining the relationship between activated identities and behavior in different social contexts. Social Psychology Quarterly, 76, 202-223. doi: $10.1177 / 0190272513493095$.

Casler, K., Bickel, L., \& Hackett, E. (2013). Separate but equal? A comparison of participants and data gathered via Amazon's MTurk, social media, and face-to-face behavioral testing. Computers in Human Behavior, 29, 2156-2160. doi:10.1016/j. chb.2013.05.009.

Chandler, J., Paolacci, G., Peer, E., Mueller, P., \& Ratliff, K. (2015). Using nonnaive participants can reduce effect sizes. Psychological Science, 26, 1131-1139. doi:10.1177/0956797615585115.

Chen, A. S., \& Hou, Y. (2016). The effects of ethical leadership, voice behavior and climates for innovation on creativity: A moderated mediation examination. Leadership Quarterly, 27, 1-13. doi:10.1016/j.leaqua.2015.10.007.

Den Hartog, D. N. (2015). Ethical leadership. Annual Review of Organizational Psychology and Organizational Behavior, 2, 409-434. doi:10.1146/annurev-orgpsych-032414-111237.

Den Hartog, D. N., \& Belschak, F. D. (2012). Work engagement and Machiavellianism in the ethical leadership process. Journal of Business Ethics, 107, 35-47. doi:10.1007/s10551-012-1296-4.

Drover, W., Franczak, J., \& Beltramini, R. F. (2012). A 30-year historical examination of ethical concerns regarding business ethics: Who's concerned? Journal of Business Ethics, 111, 431-438. doi:10.1007/s10551-012-1214-9.

Epitropaki, O., Kark, R., Mainemelis, C., \& Lord, R. G. (2017). Leadership and followership identity processes: A multilevel review. Leadership Quarterly, 28, 104-129. doi:10.1016/j. leaqua.2016.10.003.

Forsyth, D. R. (1980). A taxonomy of ethical ideologies. Journal of Personality and Social Psychology, 39, 175-184. doi:10.1037/ 0022-3514.39.1.175.
Gerpott, F. H., Balliet, D., Columbus, S., Molho, C., \& de Vries, R. E. (in press). How do people think about interdependence? a multidimensional model of subjective outcome interdependence. Journal of Personality and Social Psychology.

Gibbs, J. C., Basinger, K. S., \& Fuller, D. (1992). Moral maturity: Measuring the development of sociomoral reflection. Hillsdale New Jersey: Erlbaum.

Giessner, S. R., van Knippenberg, D., \& Sleebos, E. (2009). License to fail? How leader group prototypicality moderates the effects of leader performance on perceptions of leadership effectiveness. Leadership Quarterly, 20, 434-451. doi:10.1016/j.leaqua.2009. 03.012.

Giessner, S. R., van Knippenberg, D., van Ginkel, W. P., \& Sleebos, E. (2013). Team-oriented leadership: The interactive effects of leader group prototypicality, accountability, and team identification. Journal of Applied Psychology, 98, 658-667. doi:10. 1037/a0032445.

Giessner, S. R., van Van Quaquebeke, N., Gils, S., van Knippenberg, D., \& Kollée, J. A. J. M. (2015). In the moral eye of the beholder: The interactive effects of leader and follower moral identity on perceptions of ethical leadership and LMX quality. Frontiers in Psychology. doi:10.3389/fpsyg.2015.01126.

Graf, M. M., Schuh, S. C., Van Quaquebeke, N., \& van Dick, R. (2012). The relationship between leaders' group oriented values and follower identification with and endorsement of leaders: The moderating role of leaders' group membership. Journal of Business Ethics, 106, 301-311. doi:10.1007/s10551-011-0997-4.

Grotevant, H. D. (1987). Toward a process model of identity formation. Journal of Adolescent Research, 2, 203-222. doi:10.1177/074355488723003.

Hackman, J. R., \& Wageman, R. (2007). Asking the right questions about leadership. American Psychologist, 62, 43-47. doi:10. 1037/0003-066X.62.1.43.

Hains, S. C., Hogg, M. A., \& Duck, J. M. (1997). Self-categorization and leadership: Effects of group prototypicality and leader stereotypicality. Personality and Social Psychology Bulletin, 23, 1087-1099. doi:10.1177/01461672972310009.

Hambrick, D. C., \& Mason, P. A. (1984). Upper echelons: The organization as a reflection of its top managers. Academy of Management Review, 9, 193-206. doi:10.5465/AMR.1984.4277628.

Hansen, S. D., Alge, B. J., Brown, M. E., Jackson, C. L., \& Dunford, B. B. (2013). Ethical leadership: Assessing the value of a multifoci social exchange perspective. Journal of Business Ethics, 115, 435-449. doi:10.1007/s10551-012-1408-1.

Hayes, A. F. (2013). Introduction to mediation, moderation, and conditional process analysis. New York: Guilford Press.

Hayes, A. F. (2015). An index and test of linear moderated mediation. Multivariate Behavioral Research, 50, 1-22. doi:10.1080/ 00273171.2014 .962683$.

Hertz, S. G., \& Krettenauer, T. (2016). Does moral identity effectively predict moral behavior? A meta-analysis. Review of General Psychology, 20, 129-140. doi:10.1037/gpr0000062.

Hogg, M. A. (2001). A social identity theory of leadership. Personality and Social Psychology Review, 5, 184-200. doi:10. 1207/S15327957PSPR0503_1.

Hsee, C. K., Hatfield, E., Carlson, J. G., \& Chemtob, C. (1990). The effect of power on susceptibility to emotional contagion. Cognition and Emotion, 4, 327-340. doi:10.1080/ 02699939008408081.

Jacoby, J., \& Sassenberg, K. (2011). Interactions do not only tell us when, but can also tell us how: Testing process hypotheses by interaction. European Journal of Social Psychology, 41, 180-190. doi:10.1002/ejsp.762.

Jennings, P. L., Mitchell, M. S., \& Hannah, S. T. (2015). The moral self: A review and integration of the literature. Journal of Organizational Behavior, 36, S104-S168. doi:10.1002/job.1919. 
Junker, N. M., \& van Dick, R. (2014). Implicit theories in organizational settings: A systematic review and research agenda of implicit leadership and followership theories. Leadership Quarterly, 25, 1154-1173. doi:10.1016/j.leaqua.2014.09.002.

Kacmar, K. M., Bachrach, D. G., Harris, K. J., \& Zivnuska, S. (2011). Fostering good citizenship through ethical leadership: Exploring the moderating role of gender and organizational politics. Journal of Applied Psychology, 96, 633-642. doi:10.1037/a0021872.

Krettenauer, T., \& Hertz, S. (2015). What develops in moral identities? A critical review. Human Development, 58, 137-153. doi:10.1159/000433502.

Leavitt, K., Zhu, L., \& Aquino, K. (2015). Good without knowing it: Subtle contextual cues can activate moral identity and reshape moral intuition. Journal of Business Ethics. doi:10.1007/s10551015-2746-6.

Lee, D., Choi, Y., Youn, S., \& Chun, J. (2017). Ethical leadership and employee moral voice: The mediating role of moral efficacy and the moderating role of leader-follower value congruence. Journal of Business Ethics, 141, 47-57. doi:10.1007/s10551015-2689-y.

Litman, L., Robinson, J., \& Abberbock, T. (2017). TurkPrime.com: A versatile crowdsourcing data acquisition platform for the behavioral sciences. Behavior Research Methods, 49, 433-442. doi:10.3758/s13428-016-0727-z.

Lord, R. G., \& Brown, D. J. (2004). Leadership processes and follower self-identity. New Jersey: Lawrence Erlbaum Associates.

Lord, R. G., Brown, D. J., \& Freiberg, S. J. (1999). Understanding the dynamics of Leadership: The role of follower self-concepts in the leader/follower relationship. Organizational Behavior and Human Decision Processes, 78(3), 167-203. doi:10.1006/obhd. 1999.2832.

Mayer, D. M., Aquino, K., Greenbaum, R. L., \& Kuenzi, M. (2012). Who displays ethical leadership, and why does it matter? An examination of antecedents and consequences of ethical leadership. Academy of Management Journal, 55, 151-171. doi:10. 5465/amj.2008.0276.

Miao, Q., Newman, J., Yu, J., \& Xu, L. (2012). The relationship between ethical leadership and unethical pro-organizational behavior: Linear or curvilinear effects? Journal of Business Ethics, 116, 641-653. doi:10.1007/s10551-012-1504-2.

Mo, S., \& Shi, J. (2017). Linking ethical leadership to employees' organizational citizenship behavior: Testing the multilevel mediation role of organizational concern. Journal of Business Ethics, 141, 151-162. doi:10.1007/s10551-015-2734-x.

Mussweiler, T., \& Bodenhausen, G. V. (2002). I know you are, but what am I? Self-evaluative consequences of judging in-group and out-group members. Journal of Personality and Social Psychology, 82, 19-32. doi:10.1037//0022-3514.82.1.19.

Muthén, L. K., \& Muthén, B. O. (2012). Mplus user's guide (7th ed.). Los Angeles, CA: Muthén \& Muthén.

Newman, A., Kiazad, K., Miao, Q., \& Cooper, B. (2014). Examining the cognitive and affective trust-based mechanisms underlying the relationship between ethical leadership and organisational citizenship: A case of the head leading the heart? Journal of Business Ethics, 123, 113-123. doi:10.1007/s10551-013-1803-2.

Ng, T. H., \& Feldman, D. C. (2015). Ethical leadership: Meta-analytic evidence of criterion-related and incremental validity. Journal of Applied Psychology, 100, 948-965. doi:10.1037/a0038246.

Oppenheimer, D. M., Meyvis, T., \& Davidenko, N. (2009). Instructional manipulation checks: Detecting satisficing to increase statistical power. Journal of Experimental Social Psychology, 45, 867-872. doi:10.1016/j.jesp.2009.03.009.

Organ, D. W. (1988). Organizational citizenship behavior: The good soldier syndrome. Lexington, MA: Lexington.

Osgood, C. C., Suci, G. J., \& Tannenbaum, P. H. (1957). The measurement of meaning. Urbana: University of Illinois Press.
Peer, E., Brandimarte, L., Samat, S., \& Acquisti, A. (2017). Beyond the Turk: Alternative platforms for crowdsourcing behavioral research. Journal of Experimental Social Psychology, 70, 153-163. doi:10.1016/j.jesp.2017.01.006.

Piccolo, R. F., Greenbaum, R., Den Hartog, D. N., \& Folger, R. (2010). The relationship between ethical leadership and core job characteristics. Journal of Organizational Behavior, 31, 259-278. doi:10.1002/job.627.

Pierro, A., Ciceroa, L., Bonaiutoa, M., van Knippenberg, D., \& Kruglanskic, A. W. (2005). Leader group prototypicality and leadership effectiveness: The moderating role of need for cognitive closure. Leadership Quarterly, 16, 503-516. doi:10. 1016/j.leaqua.2005.06.002.

Podsakoff, P. M., MacKenzie, S. B., Paine, J. B., \& Bachrach, D. G. (2000). Organizational citizenship behaviors: A critical review of the theoretical and empirical literature and suggestions for future research. Journal of Management, 26, 513-563. doi:10. 1177/014920630002600307.

Podsakoff, P. M., \& Organ, D. W. (1986). Self-reports in organizational research: Problems and prospects. Journal of Management, 12, 531-544. doi:10.1177/014920638601200408.

Reed, A., \& Aquino, K. (2003). Moral identity and the expanding circle of moral regard toward out-groups. Journal of Personality and Social Psychology, 84, 1270-1286. doi:10.1037/0022-3514. 84.6.1270.

Reiley, P., \& Jacobs, R. (2016). Ethics matter: Moderating leaders' power use and followers' citizenship behaviors. Journal of Business Ethics, 134, 69-81. doi:10.1007/s10551-014-2416-0.

Resick, C. J., Hargis, M. B., Shao, P., \& Dust, S. B. (2013). Ethical leadership, moral equity judgments, and discretionary workplace behavior. Human Relations, 66, 951-972. doi:10.1177/ 0018726713481633.

Reynolds, S. J. (2008). Moral attentiveness: Who pays attention to the moral aspects of life? Journal of Applied Psychology, 93, 1027-1041. doi:10.1037/0021-9010.93.5.1027.

Robinson, M. D., \& Clore, G. L. (2001). Simulation, scenarios, and emotional appraisal: Testing the convergence of real and imagined reactions to emotional stimuli. Personality and Social Psychology Bulletin, 27, 1520-1532.

Schaubroeck, J. M., Lam, S. S., \& Peng, A. C. (2016). Can peers' ethical and transformational leadership improve coworkers' service quality? A latent growth analysis. Organizational Behavior and Human Decision Processes, 133, 45-58. doi:10. 1016/j.obhdp.2016.02.002.

Schminke, M., Ambrose, M. L., \& Neubaum, D. O. (2005). The effect of leader moral development on ethical climate and employee attitudes. Organizational Behavior and Human Decision Processes, 97, 135-151. doi:10.1016/j.obhdp.2005.03.006.

Schuh, S. C., Quaquebeke, N., Keck, N., Göritz, A. S., Cremer, D., \& Xin, K. R. (2016). Does it take more than ideals? How counterideal value congruence shapes employees' trust in the organization. Journal of Business Ethics. doi:10.1007/s10551-016-3097-7.

Shao, R., Aquino, K., \& Freeman, D. (2008). Beyond moral reasoning: A review of moral identity research and its implications for business ethics. Business Ethics Quarterly, 18, 513-540. doi:10.5840/beq200818436.

Sharif, M. M., \& Scandura, T. A. (2014). Moral identity: Linking ethical leadership to follower decision making. In L. Neider \& C. Schriesheim (Eds.), Advances in authentic and ethical leadership: Research in management (Vol. 10, pp. 155-190). Charlotte, NC: Information Age Publishing.

Shin, Y. Y. (2012). CEO ethical leadership, ethical climate, climate strength, and collective organizational citizenship behavior. Journal of Business Ethics, 108, 299-312. doi:10.1007/s10551-011-1091-7.

Siemsen, E., Roth, A., \& Oliveira, P. (2009). Common method bias in regression models with linear, quadratic, and interaction effects. 
Organizational Research Methods, 13, 456-476. doi:10.1177/ 1094428109351241.

Skarlicki, D. P., van Jaarsveld, D. D., Shao, R., Song, Y. H., \& Wang, M. (2016). Extending the multifoci perspective: The role of supervisor justice and moral identity in the relationship between customer justice and customer-directed sabotage. Journal of Applied Psychology, 101, 108-121. doi:10.1037/ap10000034.

Skubinn, R., \& Herzog, L. (2016). Internalized moral identity in ethical leadership. Journal of Business Ethics, 133, 249-260. doi:10.1007/s10551-014-2369-3.

Spencer, S. J., Zanna, M. P., \& Fong, G. T. (2005). Establishing a causal chain: Why experiments are often more effective than mediational analyses in examining psychological processes. Journal of Personality and Social Psychology, 89, 845-851. doi:10.1037/0022-3514.89.6.845.

Steffens, N. K., Schuh, S. C., Haslam, S. A., Pérez, A., \& van Dick, R. (2015). 'Of the group' and 'for the group': How followership is shaped by leaders' prototypicality and group identification. European Journal of Social Psychology, 45, 180-190. doi:10. 1002/ejsp.2088.

Stets, J. E., \& Carter, M. J. (2006). The moral identity: A principle level identity. In K. McClelland \& T. J. Fararo (Eds.), Purpose, meaning, and action: Control systems theories in sociology (pp. 293-316). New York: Palgrave Macmillan.

Stets, J. E., \& Carter, M. J. (2012). A theory of the self for the sociology of morality. American Sociological Review, 77, 120-140. doi:10.1177/0003122411433762.

Stets, J. E., \& Serpe, R. T. (2013). Identity theory. In J. DeLamater \& A. Ward (Eds.), Handbook of social psychology (pp. 31-60). Dordrecht: Springer

Stryker, S., \& Burke, P. (2000). The past, present, and future of an identity theory. Social Psychology Quarterly, 63, 284-297. doi: $10.2307 / 2695840$.

Taylor, S. G., \& Pattie, M. W. (2014). When does ethical leadership affect workplace incivility? The moderating role of follower personality. Business Ethics Quarterly, 24, 595-616. doi:10. 5840/beq201492618.

Tee, E. J., Ashkanasy, N. M., \& Paulsen, N. (2013). The influence of follower mood on leader mood and task performance: An affective, follower-centric perspective of leadership. Leadership Quarterly, 24, 496-515. doi:10.1016/j.leaqua.2013.03.005.

Thoits, P. A. (1992). Identity structures and psychological well-being: Gender and marital status comparisons. Social Psychology Quarterly, 55, 236-256. doi:10.2307/2786794.

Thornton, M. A., \& Rupp, D. E. (2015). The joint effects of justice climate, group moral identity, and corporate social responsibility on the prosocial and deviant behaviors of groups. Journal of Business Ethics. doi:10.1007/s10551-015-2748-4.

Treviño, L. K., Brown, M., \& Hartman, L. P. (2003). A qualitative investigation of perceived executive ethical leadership: Perceptions from inside and outside the executive suite. Human Relations, 56, 5-37. doi:10.1177/0018726703056001448.

Treviño, L. K., Hartman, L. P., \& Brown, M. (2000). Moral person and moral manager: How executive develop a reputation for ethical leadership. California Management Review, 42, 128-142. doi:10.2307/41166057.

Turner, J. C., Hogg, M. A., Oakes, P. J., Reicher, S. D., \& Wetherell, M. S. (1987). Rediscovering the social group: A self-categorization theory. Oxford: Blackwell.

van Gils, S., Hogg, M. A., Van Quaquebeke, N., \& van Knippenberg, D. (2015a). When organizational identification elicits moral decision-making: A matter of the right climate. Journal of Business Ethics. doi:10.1007/s10551-015-2784-0.

van Gils, S., Van Quaquebeke, N., van Knippenberg, D., van Dijke, M., \& De Cremer, D. (2015b). Ethical leadership and follower organizational deviance: The moderating role of follower moral attentiveness. Leadership Quarterly, 26, 190-203. doi:10.1016/j. leaqua.2014.08.005.

van Knippenberg, D. (2011). Embodying who we are: Leader group prototypicality and leadership effectiveness. Leadership Quarterly, 22, 1078-1091. doi:10.1016/j.leaqua.2011.09.004.

van Knippenberg, D., \& Hogg, M. A. (2003). A social identity model of leadership effectiveness in organizations. Research in Organizational Behavior, 25, 243-295. doi:10.1016/S0191-3085(03)25006-1.

van Knippenberg, D., van Knippenberg, B., De Cremer, D., \& Hogg, M. A. (2004). Leadership, self, and identity: A review and research agenda. Leadership Quarterly, 15, 825-856. doi:10. 1016/j.leaqua.2004.09.002.

van Knippenberg, D., van Knippenberg, B., De Cremer, D., \& Hogg, M. A. (2005). Research in leadership, self, and identity: A sample of the present and a glimpse of the future. Leadership Quarterly, 16, 495-499. doi:10.1016/j.leaqua.2005.06.006.

Van Quaquebeke, N., Becker, J. U., Goretzki, N., \& Barrot, C. (2017). Perceived ethical leadership affects customer purchasing intentions beyond ethical marketing in advertising due to moral identity self-congruence concerns. Journal of Business Ethics. doi:10.1007/s10551-017-3577-4.

Van Quaquebeke, N., Graf, M. M., \& Eckloff, T. (2014a). What do leaders have to live up to? Contrasting the effects of central tendency- versus ideal-based leader prototypes in leader categorization processes. Leadership, 10, 191-217. doi:10.1177/ 1742715013476081.

Van Quaquebeke, N., Graf, M. M., Kerschreiter, R., Schuh, S. C., \& Dick, R. (2014b). Ideal values and counter-ideal values as two distinct forces: Exploring a gap in organizational value research. International Journal of Management Reviews, 16, 211-225. doi:10.1111/ijmr.12017.

Van Quaquebeke, N., van Knippenberg, D., \& Brodbeck, F. C. (2011). More than meets the eye: The role of subordinates' selfperceptions in leader categorization processes. Leadership Quarterly, 22, 367-382. doi:10.1016/j.leaqua.2011.02.011.

Vandenberg, R. J., \& Lance, C. E. (2000). A review and synthesis of the measurement invariance literature: Suggestions, practices, and recommendations for organizational research. Organizational Research Methods, 3, 4-70. doi:10.1177/109442810031002.

Victor, B., \& Cullen, J. B. (1988). The organizational bases of ethical work climates. Administrative Science Quarterly, 33, 101-125. doi: $10.2307 / 2392857$.

Walker, L. J., \& Hennig, K. H. (2004). Differing conceptions on moral exemplarity: Just, brave and caring. Journal of Personality and Social Psychology, 86, 629-647. doi:10.1037/0022-3514.86. 4.629.

Walumbwa, F. O., Mayer, D. M., Wang, P., Wang, H., Workman, K., \& Christensen, A. L. (2011). Linking ethical leadership to employee performance: The roles of leader-member exchange, self-efficacy, and organizational identification. Organizational Behavior and Human Decision Processes, 115, 204-213. doi:10. 1016/j.obhdp.2010.11.002.

Welbourne, T. M., \& Paterson, T. A. (2017). Advancing a richer view of identity at work: The role-based identity scale. Personnel Psychology, 70, 315-356. doi:10.1111/peps.12150.

Williams, L. J., \& Anderson, S. E. (1991). Job satisfaction and organizational commitment as predictors of organizational citizenship and in-role behaviors. Journal of Management, 17, 601-617. doi:10.1177/014920639101700305.

Zhu, W. (2008). The effect of leadership on follower moral identity: The mediating role of psychological empowerment. Leadership Review, 8, 62-73.

Zhu, W., Treviño, L. K., \& Zheng, X. (2016). Ethical leaders and their followers: The transmission of moral identity and moral attentiveness. Business Ethics Quarterly, 26, 95-115. doi:10. 1017/beq.2016.11. 